\section{Commentary: What is more critical: Forward flow or backward flow? Contradictory hemodynamics with mechanical prostheses}

\author{
W. R. Eric Jamieson, MD, FRCS(C), FACS
}

Hatoum and colleagues ${ }^{1}$ seem to be struggling with the fact that forward flow turbulence, blood damage, and reduced anticoagulation are somewhat contradictory. ${ }^{1}$ This article, though, is not a revelation. In a particle image velocimetry dynamic study published by Akutsu and Matsumoto, ${ }^{2}$ the authors found higher Reynolds numbers in the On-X prosthesis (CryoLife Inc, Kennesaw, Ga) than the St Jude Medical (HP Masters series; St Paul, Minn) prosthesis. Hatoum and colleagues ${ }^{1}$ correctly point out that the bulk fluid dynamic properties of gradient and effective orifice area are not directly and always related to turbulence as measured by the Reynolds number.

The mechanics of opening during the cardiac cycle and closing, as pointed out by Hatoum and colleagues, ${ }^{1}$ should be noted as influenced entirely by design. The On-X prosthesis design intends that the leaflets react to local fluid environment and do not become pinned against an artificial stop.

The authors want to make the turbulence measures relate to hemolysis but provide no clinical evidence of this, only bench studies that look at shear-related hemolysis. This would make one suppose that the St Jude Medical prosthesis should have lower evidence of hemolysis than the On-X prosthesis. However, that is not the case and the opposite is actually true, as shown by several investigators in studies of multiple prostheses, namely Birnbaum and colleagues ${ }^{3}$ and Skoularigis and colleagues. $^{4}$

\footnotetext{
From the Department of Surgery, University of British Columbia, and the Vancouver Coastal Health Research Institute, Vancouver, British Columbia, Canada. Disclosures: Author has nothing to disclose with regard to commercial support. Received for publication Jan 21, 2020; accepted for publication Jan 21, 2020 Address for reprints: W. R. Eric Jamieson, MD, FRCS(C), FACS, Vancouver Coastal Health Research Institute, 2635 Laurel St, 6th Floor, Vancouver, British Columbia V5Z1M9 Canada (E-mail: wreric.jamieson@gmail.com).

J Thorac Cardiovasc Surg 2022;164:e27-8 $0022-5223 / \$ 36.00$

Copyright $(C) 2020$ Published by Elsevier Inc. on behalf of The American Association for Thoracic Surgery

https://doi.org/10.1016/j.jtcvs.2020.01.059
}

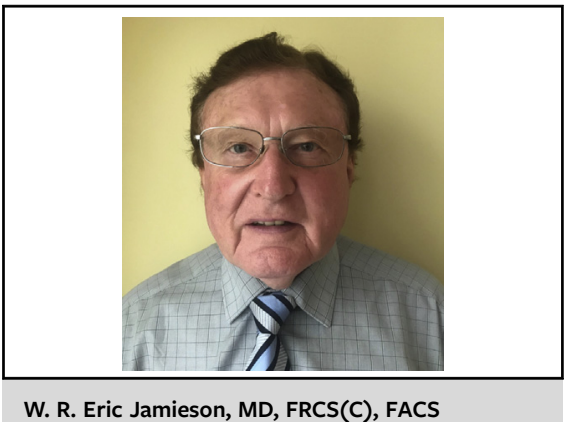

CENTRAL MESSAGE

Hemolysis assessed by forward and backward flow turbulence.

The authors identify their problem, though, in that they did not examined backflow. Backflow is likely more important to hemolysis than forward flow due to the high shear in leakage jets. This thought is based on historical clinical observations of hemolysis. When first reported with ball-incage prostheses, which have no closed leakage, hemolysis (represented by serum lactic dehydrogenase) was observed at a higher rate in aortic prostheses than mitral prostheses, indicating that it was due to forward shear flow. However, this phenomenon shifted with the advent of the titling disc and then the bileaflet prostheses, all of which have designed and controlled closed leakage. Now hemolysis became more prevalent in mitral prostheses than in aortic prostheses. Forward flow gradients had been reduced to the point that there was much less production of blood damage. The gradients in backflow became much higher and the leakage jets became of high velocity and turbulent (causing much more damage in the mitral position due to the higher driving forces). Presently, blood damage is more a mitral problem than an aortic problem.

Hinge flow is important throughout the cycle to avoid stasis in all locations and reduce fluid shear work to avoid both thrombus formation and blood damage.

The On-X prosthesis in the aortic position has hemolysis measures in the normal range and approaching those of the tissue bioprostheses. The St Jude Medical prosthesis has higher hemolysis. This is why a single in vitro test is wholly inadequate to describe clinical performance. This article is interesting but not clinically informative.

\section{References}

1. Hatoum H, Maureira P, Dasi LP. A turbulence in vitro assessment of On-X and St Jude Medical prostheses. J Thorac Cardiovasc Surg. 2020;159:88-97. 
2. Akutsu T, Matsumoto A. Influence of three mechanical bileaflet prosthetic valve designs on the three-dimensional flow field inside a simulated aorta. J Artif Organs. 2010;13:207-17.

3. Birnbaum D, Lackovics A, Heidt M, Oelert H, Laufer G, Greve H, et al. Examination of hemolytic potential with the On- $\mathrm{X}^{(\mathrm{R})}$ prosthetic heart valve. J Heart Valve Dis. 2000;9:142-5.
4. Skoularigis J, Essop MR, Skudicky D, Middlemost SJ, Sareli P. Frequency and severity of intravascular hemolysis after left-sided cardiac valve replacement with Medtronic Hall and St. Jude Medical prostheses, and influence of prosthetic type, position, size and number. Am J Cardiol. 1993; $71: 587-91$. 